\title{
Callo: The first known case of ambiguous genitalia to be surgically repaired in the history of Medicine, described by Diodorus Siculus
}

\author{
Georgios K. Markantes, ${ }^{1}$ Efthimios Deligeoroglou, ${ }^{2}$ Anastasia K. Armeni, ${ }^{1}$ \\ Vasiliki Vasileiou, ${ }^{3}$ Christina Damoulari, ${ }^{1}$ Angelina Mandrapilia, ${ }^{1}$ \\ Fotini Kosmopoulou, ${ }^{1}$ Varvara Keramisanou, ${ }^{1}$ Danai Georgakopoulou, ${ }^{1}$ \\ George Creatsas, ${ }^{2}$ Neoklis A. Georgopoulos ${ }^{1}$
}

${ }^{1}$ Division of Reproductive Endocrinology, Department of Obstetrics and Gynecology, University of Patras Medical School, Patras; ${ }^{2} 2^{\text {nd }}$ Department of Obstetrics and Gynecology, Division of Pediatric, Adolescent Gynecology and Reconstructive Surgery, University of Athens, Medical School, Aretaieion Hospital, Athens, ${ }^{3} 1^{\text {st }}$ Department of Endocrinology, Diabetes Centre, "Alexandra" Hospital, Athens

\section{LITERAL DOCUMENTATION OF CALLO: A CASE OF FEMALE TO MALE SEXUAL TRANSFORMATION DESCRIBED BY DIODORUS SICULUS}

Diodorus Siculus (Diodoros Sikeliotes) was a Greek historian and writer who lived in the $1^{\text {st }}$ century B.C. He is renowned for his universal history, "Bibliotheca Historica" (Historical Library), in which cases of sexual reassignment occurring around his time were included.

Among the cases of androgynism gathered by

Key words: Ambiguous genitalia, Androgynism, Diodorus Siculus, Disorders of sexual development, $5 \alpha$ reductase deficiency, Heterosexual puberty, $17 \beta \mathrm{HSD}$ deficiency

Address for correspondence:

Neoklis A. Georgopoulos, Department of Obstetrics and Gynecology, Division of Reproductive Endocrinology, University of Patras Medical School, Rio-26500, Patras, Greece Tel.: 2610-999835, Fax: 2610-993854, e-mail: neoklisg@hol.gr Received:14-05-2015, Accepted:19-05-2015

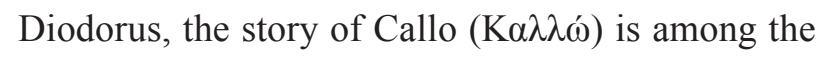
most intriguing ones. The sequence of events was described as follows:

"There was an Epidaurian, Callo, who was supposed to be a girl. Now the orifice with which women are provided, had in her case no opening, but beside the so-called pecten she had from birth a perforation through which she excreted the liquid residues. On reaching maturity she became the wife of a fellow citizen. For two years she lived with him, and since she was incapable of intercourse as a woman, was obliged to submit to unnatural embraces. Later, a tumor appeared on her genitals and because it gave rise to great pain a physician was called in. He cut into the swollen area, whereupon a man's privates protruded. He took steps to remedy the remaining deficiencies. First of all, cutting into the glans he made a passage into the urethra, and inserting a silver catheter drew off the liquid residues. Then, by scarifying the perforated area, he brought the parts together Callo laid aside her loom-shuttles and all other instruments of woman's work, and taking in their stead the garb and status of a man changed her name to Callon". ${ }^{1}$ 


\section{DIFFERENTIAL DIAGNOSIS OF THE CASE "CALLO"}

Callo was apparently born with ambiguous or female external genitalia. She was thus raised as a female during childhood and was married to a man close to the time of puberty as was the custom of the era. However, Diodorus clearly cites the existence of male genitalia appearing after the physician's intervention. We can therefore assume that Diodorus described a case of a disorder of sexual development (DSD) manifesting as heterosexual puberty.

Differential diagnosis of this case includes an adrenal or gonadal virilising tumor, gonadal dysgenesis, true hermaphroditism as well as male and female pseudohermaphroditism.

Taking into account the evidence provided by the writer, we can exclude with certainty the possibility of a virilising tumor, as the presence of such tumors for a long period without proper treatment is incompatible with life. Although gonadal dysgenesis cannot be completely ruled out, it is considered unlikely as it rarely arises because of the large amount of androgens needed to provoke the clinical manifestations of heterosexual puberty. As for true hermaphrodites, they tend to develop female characteristics during puberty and this phenotype prevails for the rest of their lives, while no case of heterosexual puberty has ever been reported in this context. The presence of testes in our case allows us to reject female pseudohermaphroditism (46,XX DSD).

Therefore, male pseudohermaphroditism (46,XY DSD) is the most likely scenario in such cases, as patients (who have male gonads) fail to develop male sexual characteristics in utero and during childhood - when androgen levels are relatively low — and present an impressive transformation with rapid development of male secondary sexual characteristics in puberty due to the presence of high amounts of physiologically active androgens. With the assumption that heterosexual puberty has never been reported in androgen insensitivity syndrome (AIS), the defect probably numbers among the disorders affecting androgen synthesis. Among all enzyme deficiencies in the steroidogenic pathways, only those of $17 \beta$ hydroxysteroid dehydrogenase (HSD17B3), the enzyme converting androstenedione (A) to testosterone
(T), or 5a reductase type 2 , the enzyme converting testosterone to dihydrotestosterone (DHT), can lead to clinical phenotypes characterized by ambiguous genitalia and heterosexual puberty.

5 a reductase type 2 is highly expressed in gestation and is responsible for the production of DHT, which is the major determinant of intrauterine male external genitalia formation. Therefore, lack of this enzyme results in decreased production of DHT and is correlated with pronounced ambiguity of the infant's external genitalia, simulating those of a female. ${ }^{2}$

When 5a reductase type 2 deficient males enter puberty, large accumulated amounts of T are converted to DHT by 5 a reductase type 1 , resulting in dramatic phenotypic changes. Unlike 5a reductase type 2, type 1 is not expressed in utero. An age-dependent increase in its expression has been reported, which renders its action measurable during puberty and for the rest of the individual's life, thus compensating for 5 a reductase type 2 deficiency. ${ }^{3}$

Heterosexual puberty in cases of HSD17B3 deficiency is due to isoenzyme HSD17B5. Although HSD17B3 converts androstenedione to testosterone in the testes, HSD17B5 is responsible for extragonadal production of testosterone. Furthermore, there is an age-dependent regulatory transcription mechanism of HSD17B3 and HSD17B5 isoenzymes, with the former decreasing and the latter increasing with age. ${ }^{4}$ Hence, HSD17B3 deficiency, besides manifesting less striking genital ambiguity, does not lead to notable changes during puberty, as androstenedione is a weak androgen and HSD17B3 expression is significantly repressed during puberty.

\section{SURGICAL TREATMENT OF CALLO'S GENITAL AMBIGUITY - ASSOCIATION WITH MODERN SEX REASSIGNMENT SURGERY}

Due to the rarity of the syndrome, current literature regarding 5a reductase type 2 deficiency is sparse. In most of the cases, external genitalia do not differ from the description of Diodorus.

Surgical correction of ambiguous genitalia in this special group of patients depends on the phenotypic findings and gender at the time of diagnosis.

For patients raised as females, the age at the time 
of diagnosis plays a significant role in the course of decision making. ${ }^{5}$

If the diagnosis is made before the child enters puberty, gonadectomy and surgical correction of the external genitalia are indicated and must be performed as soon as possible in order to avoid masculinization. Generally, the procedure involves clitorectomy with preservation of glandular enervation and blood supply as well as surgical correction of the urethra and urogenital sinus. Moreover, vaginoplasty is essential in order to provide the opportunity for a healthy sexual life. There are numerous techniques both surgical and non-surgical that have been proposed for the creation of a neovagina. Appropriate estrogen-only Hormone Replacement Therapy must be administered to all patients assigned the female gender until the $50^{\text {th }}$ year of age. ${ }^{5}$

There are data showing that many patients, initially raised as females in whom diagnosis is made after they reach puberty, undergo a gender identity change from female to male due to the effect of androgens on the brain. Long-term careful psychological evaluation is essential in order to aid the patient in making a well thought-out decision. ${ }^{5}$ If the male gender is finally chosen, as in the case of Callo, the appropriate surgical correction of the external genitalia is performed.

\section{CONCLUSION}

Diodorus Siculus describes the first recorded surgical repair of a case of heterosexual puberty due to either 5a reductase type 2 or HSD17B3 deficiency. The surgical procedure performed in Callo does not have significant discrepancies from the principles of modern surgical management, besides an early diagnosis, emphasizing the high scientific standards achieved by ancient Greek medicine.

\section{REFERENCES}

1. Siculus Diodorus, Oldfather CH (Translator) 1935 Library of History: Loeb Classical Library. Harvard University Press, Cambridge, MA.

2. Imperato-McGinley J, Zhu YS, 2002 Androgens and male physiology the syndrome of 5alpha-reductase-2 deficiency. Mol Cell Endocrinol 198: 51-59.

3. Thiele S, Hoppe U, Holterhus PM, Hiort O, 2005 Isoenzyme type 1 of 5 alpha-reductase is abundantly transcribed in normal human genital skin fibroblasts and may play an important role in masculinization of 5alpha-reductase type 2 deficient males. Eur J Endocrinol 152: 875-880.

4. George MM, New MI, Ten S, Sultan C, Bhangoo A, 2010 The clinical and molecular heterogeneity of 17ßHSD-3 enzyme deficiency. Horm Res Paediatr 74: 229-240.

5. Costa EMF, Domenice S, Sircili MH, Inacio M, Mendonca BB, 2012 DSD due to $5 \alpha$-reductase 2 deficiency - from diagnosis to long term outcome. Seminars in reproductive medicine 30: 427-431. 